\title{
Triaxial analysis of residual stress in surface layers after high feed machining using X-ray diffractometer
}

\author{
Michal Sajgalik ${ }^{1,{ }^{*}}$, Tatiana Czanova ${ }^{1}$, Lucia Zauskova ${ }^{1}$, Mario Drbul ${ }^{1}$, Marek Sadilek $^{2}$, \\ Jan Valicek $^{2}$ \\ ${ }^{1}$ Department of Machining and Manufacturing Technology, University of Zilina, Univerzitna 1, \\ 01026 Zilina \\ ${ }^{2}$ Department of Machining, Assembly and Engineering Metrology, Technical University of Ostrava, \\ 17. Listopadu 15/2172, 70833 Ostrava - Poruba
}

\begin{abstract}
Continuously increasing of productivity is main cause of finding of new ways and methods of machining. High feed machining (HFM) is one of methods of high-productivity machining developed to achieve higher metal removal rates and decrease machining time. Each machining or treatment operation introduces residual stress into the material and its surface layers. Roughing methods of machining generate tensile residual stress obviously. Tensile character of residual stress is not suitable for functional properties of produced parts. In some cases, finishing methods of machining can improve residual stress to suitable character. New detection method of residual stress by applying of $\mathrm{x}$-ray diffraction allows to measure residual stress as triaxial tensor and distribution of residual stress. When we know analyse the residual stress thoroughly, we can design right finishing method and so improve the character of residual stress. This article is focused on analysing given measuring method of residual stress in triaxial direction and next possibilities of their eventual improvement.
\end{abstract}

Keywords: x-ray diffractometry, residual stress, stress tensor

\section{Introduction}

Given that there is currently increasing serial production of components, machining technologies are also being developed. One of them is high-feed milling technology, which is characterized by material removal at a low depth of cut and high feed per tooth. During high-feed milling, stresses are formed in the material. These stresses, also called residual stresses, exist in the material even when the material is not already loaded by external forces. The common cause of these stresses is the manufacturing process (machining technologies, welding, forming, heat treatment, etc.). [1, 2]

Residual stresses are formed in the surface layers only if there is a plastic deformation in the surface layer. Whether the stress will be tensile or compressive depends on how the

\footnotetext{
*Corresponding author: michal.sajgalik@fstroj.uniza.sk

Reviewers: Ivan Kuric, Tomáš Lack
} 
deformation has been occurred. It can be caused by the following factors: thermal phase transformation, thermal and plastic deformation, and mechanical deformation (shown in Fig. 1). In the case of thermal phase transformation, the residual stress is caused by a volume change (Fig. 1(a)). If the phase change causes a decrease in volume, the surface layer will want to contract, but the underlying bulk material will resist. In the result the surface layer will be under tension. In this case, the tensile stress is produced. If the phase transformation causes an increase in volume, the residual stress will be compressive. This is the case with the conventional heat treatment of steel. In the model of thermal and plastic deformation, the unit event heat will cause expansion of the surface layer. The expansion is relieved (whilst the heating is maintained) by plastic flow, which is restricted only to the surface layer. After the heat is removed, the surface layer will contract, resulting in a tensile residual stress (Fig. 1(b)). In the model of mechanical deformation, the residual stress is compressive after the surface layer is compressed by some form of mechanical action (Fig. 1(c)). There are no heating effects. Processes consisting of only chemical unit events produce zero residual stress [1-3].

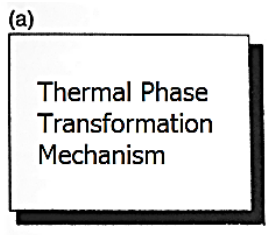

(b)

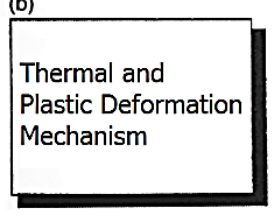

(c)

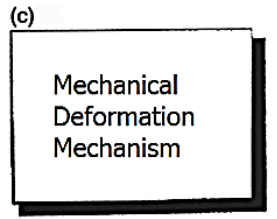

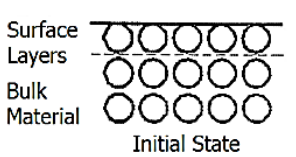

Initial State

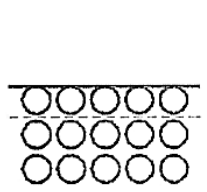

Initial State

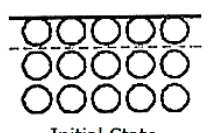

Initial State

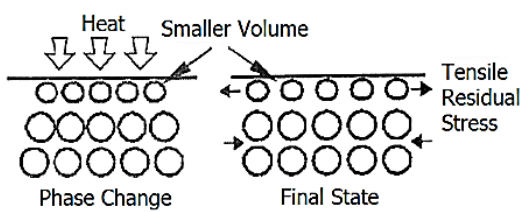

Heat \& Deformation
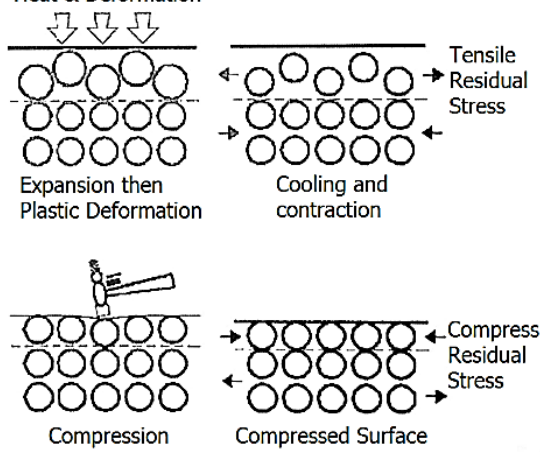

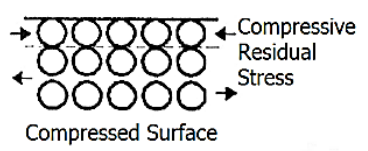

Fig. 1. The residual stress formation models [3]

Many detection methods are used to detect the residual stress in material. One of them is the non-destructive method of X-ray diffractometry. The principle is based on the influence of residual stress in the crystallographic lattice and distance of its planes (d), which is measured. As long as the stress is zero, the distance of crystallographic planes only depends on the material properties. The planes distances vary by the influence of the residual stress. Any change in the crystallographic planes distance d results in the corresponding diffraction angle. The incident X-ray beam penetrates the surface layers of the material, where depending on the crystallographic planes distance it will diffract to the diffraction cone recorded on the detectors [4-7].

The triaxial residual stress measurement is characteristic by measuring at various angles $\varphi$, when it is possible to gain a stress tensor containing normal and shear stress components acting at the measurement point. When the measurements for three directions in the point are recorded, (typically $\varphi=0^{\circ}, 45^{\circ}, 90^{\circ}$ ), the full stress tensor is calculated, comprising the normal stress for each of the measured directions, and the shear stresses also $[2,5,8,9]$. 
The stress tensor in material can be written:

$$
\left[\begin{array}{lll}
\sigma_{11} & \tau_{12} & \tau_{13} \\
\tau_{21} & \sigma_{22} & \tau_{23} \\
\tau_{31} & \tau_{32} & \sigma_{33}
\end{array}\right]=\left[\begin{array}{lll}
\sigma_{x x} & \tau_{x y} & \tau_{x z} \\
\tau_{y x} & \sigma_{y y} & \tau_{y z} \\
\tau_{z x} & \tau_{z y} & \sigma_{z z}
\end{array}\right]
$$

where $\sigma$ is normal stress component and $\tau$ is the shear stress component acting in the place of measurement (as shown in Fig. 2) [2, 10].

When calculating the stress tensor, it is generally assumed that the stress normal to the specimen surface $\left(\sigma_{33}\right)$ is zero. There can be no stress normal to a free surface in equilibrium. However, a stress can be maintained in this surface-normal direction at some depth below the surface. Hence for some deeply penetrating measurements (tens of microns), it is possible that a non-zero value of stress could be present. In this case, calculation of the stress tensor requires knowledge of the stress-free lattice parameter $\mathrm{d}_{0}$ for the examined material $[5,6,11]$.

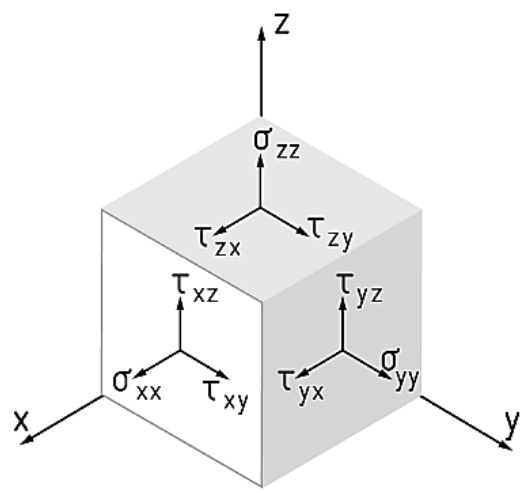

Fig. 2. Normal and shear residual stress components acting in the volume of material

In most practical applications, such as surfaces created by machining, grinding or quenching, the crystallographic lattice plane distance changes due to plastic deformation or heat treatment, which prevents the independent detection of the stress-free plane distance with sufficient precision. Extensive data collection and dependence on knowledge of $\mathrm{d}_{0}$ limits the method of determining a complete stress tensor primarily for research purposes $[8,12,13]$.

\section{Experimental measurements}

Samples made of X37CrMoV5-1 (19 552) steel hardened and tempered to hardness of 45 HRC with dimensions $40 \times 40 \times 340 \mathrm{~mm}$, were used as experimental material. The samples were milled with a $\Phi 25 \mathrm{~mm}$ 2-insert holder and JDMW09T320ZDSR-FTVP30RT highfeed inserts. When selecting cutting parameters, a constant cut speed $\mathrm{v}_{\mathrm{c}}=200 \mathrm{~m} \cdot \mathrm{min}^{-1}$ was selected. A cut depth of $a_{p}=0,5 \mathrm{~mm}$ was chosen, with a feed per tooth of $\mathrm{f}_{\mathrm{z}}=0,5 \mathrm{~mm} ; 1$ $\mathrm{mm} ; 1,5 \mathrm{~mm} ; 2 \mathrm{~mm}$.

Following the high-feed milling operations on the vertical 3-axis CNC milling machine and subsequent cleaning and degreasing of milled surfaces, residual stresses were measured on the samples by triaxial analysis on a x-ray diffractometer (Fig. 3). Triaxial detection of residual stresses consisted of measurements at three $\varphi$ angles $\left(0^{\circ}, 45^{\circ}, 90^{\circ}\right)$. The stress tensor with corresponding error has been then created. The software of measuring device generates stress tensor with the condition that the value of $\sigma_{33}$ is zero. For the measurement, 
a $\mathrm{Cr} \mathrm{K} \alpha$ lamp and collimator of $1 \mathrm{~mm}$ diameter were selected. Residual stresses in the samples were measured in the milling head onset area, center of the milled area, and milling head exit area.

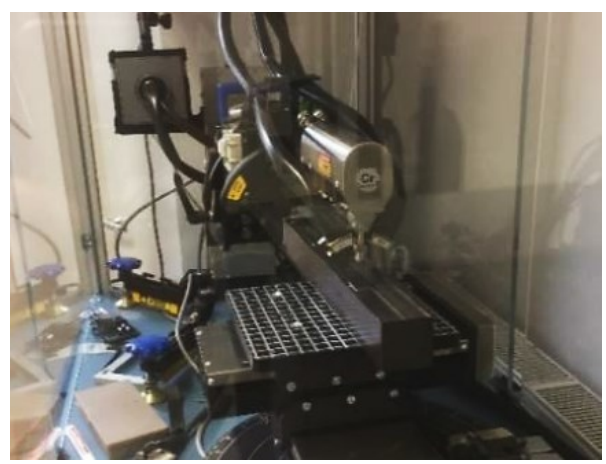

Fig. 3. Sample on the measuring table of $x$-ray diffractometer

Stress tensor for the parameter of $\mathrm{f}_{\mathrm{z}}=0,5 \mathrm{~mm}$ :

Stress tensor

Error

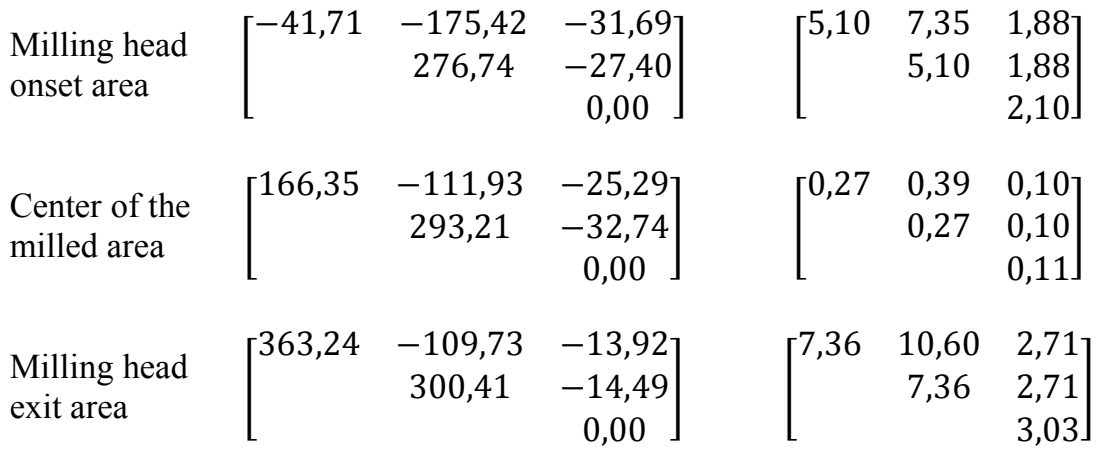

Stress tensor for the parameter of $\mathrm{f}_{\mathrm{z}}=1 \mathrm{~mm}$ :

Stress tensor

Error

$\begin{array}{llll}\begin{array}{l}\text { Milling head } \\ \text { onset area }\end{array} & {\left[\begin{array}{ccc}177,00 & -211,23 & -19,76 \\ & 321,13 & -28,25 \\ & & 0,00\end{array}\right]} & {\left[\begin{array}{ccc}6,56 & 9,44 & 2,41 \\ & 6,56 & 2,41 \\ & & 2,70\end{array}\right]} \\ \begin{array}{l}\text { Center of the } \\ \text { milled area }\end{array} & {\left[\begin{array}{ccc}32,75 & -74,03 & -5,17 \\ & 303,52 & -22,00 \\ & & 0,00\end{array}\right]} \\ \begin{array}{l}\text { Milling head } \\ \text { exit area }\end{array} & {\left[\begin{array}{lll}138,48 & -191,48 & 11,25 \\ & 307,50 & -18,31 \\ & & 0,00\end{array}\right]} & {\left[\begin{array}{lll}12,99 & 18,71 & 4,78 \\ & 12,99 & 4,78 \\ & & 5,35\end{array}\right]}\end{array}$


Stress tensor for the parameter of $\mathrm{f}_{\mathrm{z}}=1,5 \mathrm{~mm}$ :

Stress tensor

Milling head

$\left[\begin{array}{ccc}-23,09 & -143,74 & -4,00 \\ & 467,00 & -10,32 \\ & & 0,00\end{array}\right]$

Center of the
milled area $\quad\left[\begin{array}{ccc}146,22 & -161,01 & -4,87 \\ & 469,29 & -29,85 \\ & & 0,00\end{array}\right]$

Milling head
exit area $\quad\left[\begin{array}{ccc}-135,60 & -5,84 & 19,09 \\ & 511,29 & -31,82 \\ & & 0,00\end{array}\right]$

Error

$\left[\begin{array}{lll}2,59 & 3,73 & 0,95 \\ & 2,59 & 0,95 \\ & & 1,07\end{array}\right]$

Stress tensor for the parameter of $\mathrm{f}_{\mathrm{z}}=2 \mathrm{~mm}$ :

Stress tensor

Error

$\begin{array}{llll}\begin{array}{l}\text { Milling head } \\ \text { onset area }\end{array} & {\left[\begin{array}{ccc}102,21 & -323,61 & -12,96 \\ & 391,16 & -14,43 \\ & & 0,00\end{array}\right]} & {\left[\begin{array}{ccc}7,43 & 10,71 & 2,73 \\ & 7,43 & 2,73 \\ & & 3,06\end{array}\right]} \\ \begin{array}{l}\text { Center of the } \\ \text { milled area }\end{array} & {\left[\begin{array}{ccc}-178,84 & -115,58 & -16,32 \\ & 385,42 & -3,25 \\ & & 0,00\end{array}\right]} & {\left[\begin{array}{ccc}7,51 & 10,82 & 2,76 \\ & 7,51 & 2,76 \\ & & 3,09\end{array}\right]} \\ \begin{array}{l}\text { Milling head } \\ \text { exit area }\end{array} & {\left[\begin{array}{lll}188,63 & -72,74 & -4,13 \\ & 375,36 & -34,86 \\ & & 0,00\end{array}\right]} & {\left[\begin{array}{lll}1,96 & 2,82 & 0,72 \\ & 1,96 & 0,72 \\ & & 0,81\end{array}\right]}\end{array}$

From the stress tensors, the graphical dependence of the normal residual stress components oriented in the direction of the milling $\left(\sigma_{\mathrm{yy}}\right)$ and the changing feed per tooth was made.

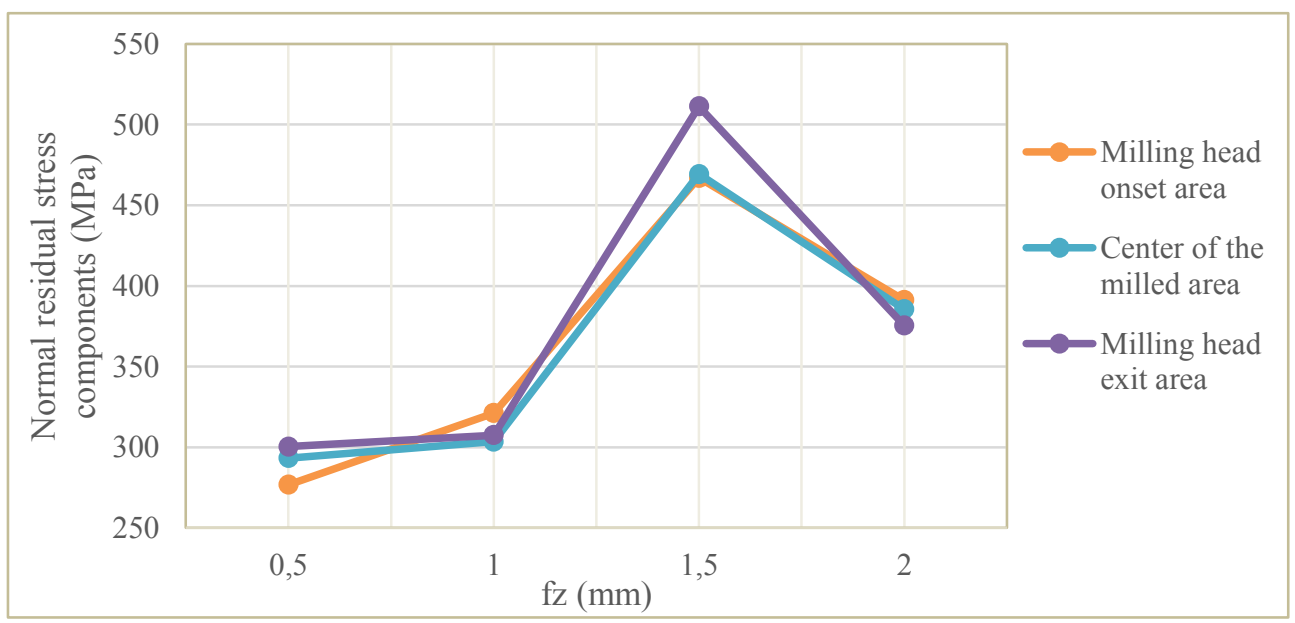

Fig. 4. Dependence of the normal residual stress components oriented in the direction of the milling and the changing feed per tooth 
From the graph in Fig. 4 we can see, that the stresses in the measured places showed tensile character. Furthermore, we can see that the normal residual stress components $\sigma_{\mathrm{yy}}$ also grow with the increasing feed per tooth. The difference is only for the selected $f_{z}=2$ $\mathrm{mm}$, where the stresses decreased. The decrease could be due to the fact that the $f_{z}=2 \mathrm{~mm}$ was too high for the machined material and chosen inserts. The lowest values were measured at $\mathrm{f}_{\mathrm{z}}=0,5 \mathrm{~mm}$, namely $276,74 \mathrm{MPa}$ in the milling head onset area, 293,21 MPa in the center of the milled area, and $300,41 \mathrm{MPa}$ in the milling head exit area. Then a sample machined with $\mathrm{f}_{\mathrm{z}}=1 \mathrm{~mm}$ was measured. Stress of $321,13 \mathrm{MPa}$ was measured in the milling head onset area, 303,52 MPa in the center of the milled area, and 307,50 MPa in the milling head exit area. The highest values were measured at $\mathrm{f}_{\mathrm{z}}=1,5 \mathrm{~mm}$, namely $467,00 \mathrm{MPa}$ in the milling head onset area, 469,29 MPa in the center of the milled area, and 511,29 MPa in the milling head exit area. For $\mathrm{f}_{\mathrm{z}}=2 \mathrm{~mm}$, a value of $391,16 \mathrm{MPa}$ was measured in the milling head onset area, $385,42 \mathrm{MPa}$ in the center of the milled area, and $375,36 \mathrm{MPa}$ in the milling head exit area.

\section{Conclusion}

The selected experimental material caused machining problems and the quality of the machined surface has been lower. Improvement of the quality and functional properties of the machined surface, including the residual stresses, could be realized by the use of inserts with different geometry, or by the choice of more suitable cutting parameters. Subject of an article is the method of triaxial measurement of residual stresses. Triaxial analysis of residual stress can be used in closer examination of the impact of cutting tool on the residual stress formation in the material. Method offers many possible applications in order to verificate and extent the theoretical knowledge in this topic.

This article was funded by the University of Žilina project APVV 15-0405 - "Complex use of X-ray diffractometry for identification and quantification of functional properties of dynamically loaded structural elements from important technical materials" and project of University of Zilina: OPVav2009/2.2/04-SORO number (26220220101) - "Intelligent system for nondestructive technologies on evaluation for the functional properties of components of X-ray diffraction" and KEGA project $025 Z ̌ U-4 / 2017$ Integration of innovative detectional-visaulization multi-disciplinary technologies as on-line tool for learning of progressive $\mathrm{CNC}$ technologies.

\section{References}

1. B. Griffiths, Manufacturing Surface Technology: Surface Integrity \& Functional Performance. (Penton Press, 256 p., 2001)

2. W. Grzesik, Advanced Machining Processes of Metallic Materials: Theory, Modelling and Applications. (Elsevier, 446 p., 2008)

3. A. Czan, E. Tillova, J. Semcer, J. Pilc, Surface and subsurface residual stresses after machining and their analysis by $x$-ray diffraction. Communications - Scientific Letters of the University of Zilina, 69-76 (2013)

4. N. Ganev, I. Kraus, X-ray diffraction measurement of residual stresses. Material Structure 9 (2), (2002)

5. A. Czan, M. Sajgalik, J. Holubjak, M. Piesova, T. Czanova, Simulation of residual stresses in surface and subsurface layer after machining. Communications - Scientific letters of the University of Zilina, 95-100 (2016) 
6. L. Jakubovicova, M. Saga, Computational analysis of contact stress distribution in the case of mutual stewing of roller bearing rings. Novel Trends in Production Devices and Systems, Applied Mechanics and Materials 474, 363-368 (2014)

7. M. Harnicarova, J. Valicek, R. Cep, et. al., Surface integrity analysis in laser beam cutting process. Metal 2013: $22^{\text {nd }}$ International conference on metallurgy and materials, 1057-1062 (2013)

8. P. S. Prevey, P.W. Mason, D.J. Hornbach, J.P. Molkenthin, Effect of prior machining deformation on the development of tensile residual stresses in weld-fabricated nuclear components. Journal of Materials Engineering and Performance 5 (1), $51-56$ (1996)

9. R. Cep, L. Ocenasova, J. Novakova, L. Perkovska, A. Czan, D. Stancekova, Intereupted Machining Tests of Ceramic Cutting Tools. TMT 2009 Proc., Hammamet, 13 (1), 733-736, ISSN 1840-4944 (2009)

10. A. Czan, M. Sajgalik, A. Martikan, J. Mrazik, Observation of dynamic processes in cutting zone when machining nickel alloys. Communications - Scientific Letters of the University of Zilina 16 (3A), 161-168 (2014)

11. D. Mital, J. Zajac, Z. Mitalova, Monitoring influence of selected parameters on surface quality after polymer powder coating. MM Science Journal 2016, 1077-1081 (2016)

12. Gorog, A., Stancekova, D., Kapustova, M. Gorogova, I., Miturska, Influence of Selected Cutting Conditions on Cutting Forces. Advances In Science And TechnologyResearch Journal 11 (1), 179-185, ISSN 2299-8624

13. Czán, A., Martikáň, A., Holubják, J., Struhárňansky, J.: Identification of stress and structure properties in surface and subsurface layers of nuclea reactor austenitic steel. Manufacturing Technology 14 (3), 2776-281, ISSN 1213-2489 (2014) 